\title{
Validity of conventional endoscopy using "non-extension sign” for optical diagnosis of colorectal deep submucosal invasive
}

\section{cancer}

\section{(c) $(>)$}

Authors

Takashi Hisabe $^{1}$, Sumio Tsuda², Toshio Hoashi ${ }^{3}$, Hiroshi Ishihara ${ }^{1}$, Kazutomo Yamasaki ${ }^{1}$, Tatsuhisa Yasaka ${ }^{1}$, Fumihito Hirai $^{1}$, Toshiyuki Matsui ${ }^{1}$, Kenshi Yao ${ }^{4}$, Hiroshi Tanabe ${ }^{5}$, Akinori Iwashita ${ }^{5}$

Institutions

1 Department of Gastroenterology, Fukuoka University Chikushi Hospital, Chikushino, Japan

2 Endoscopy unit, General Health Examination Center, Okayama Saiseikai General Hospital, Okayama, Japan

3 Hoashi Gastrointestinal Medical Clinic, Chikushino, Japan

4 Department of Endoscopy, Fukuoka University Chikushi Hospital, Chikushino, Japan

5 Department of Pathology, Fukuoka University Chikushi Hospital, Chikushino, Japan

submitted 8.6.2017

accepted after revision 19.9.2017

\author{
Bibliography \\ DOI https://doi.org/10.1055/s-0043-121881 | \\ Endoscopy International Open 2018; 06: E156-E164 \\ (c) Georg Thieme Verlag KG Stuttgart · New York \\ ISSN 2364-3722
}

\section{Corresponding author}

Takashi Hisabe, Department of Gastroenterology, Fukuoka University Chikushi Hospital, 1-1-1 Zokumyoin, Chikushino, Fukuoka 818-8502, Japan

Fax: +81-92-929-2630

hisabe@cis.fukuoka-u.ac.jp

\section{ABSTRACT}

Background and study aims The non-extension sign relates to a localized increase in thickness and rigidity due to deep submucosal invasive (SM-d: depth of $1000 \mu \mathrm{m}$ or more) cancer. The present study aimed to evaluate the efficacy of the non-extension sign in assessing the optical diagnosis of colorectal SM-d cancer.

Patients and methods We retrospectively analyzed 309 patients with 315 early colorectal cancers that had been endoscopically or surgically resected. The non-extension sign was judged from chromoendoscopy (CE) using conventional white-light imaging with indigo carmine, and is taken to be positive when any one of the findings of rigidity of a circular arc, trapezoid elevation, or converging mucosal folds are seen. We assessed comparing the accuracy of CE, magnifying chromoendoscopy (M-CE), and magnifying narrow-band imaging (M-NBI) for the optical diagnosis of colorectal SM-d cancer.

Results Sensitivity, specificity, and accuracy for the diagnosis of SM-d cancer were $66.0 \%, 95.8 \%$, and $86.3 \%$ for CE; $80 \%, 90.7 \%$, and $87.3 \%$ for $\mathrm{M}-\mathrm{CE}$; and $65.0 \%, 94.4 \%$, and $85.1 \%$ for $\mathrm{M}-\mathrm{NBI}$, respectively. The specificity of CE was significantly higher than that of M-CE $(P=0.034)$. The sensitivity of $M-C E$ was significantly higher than that of CE $(P=0.026)$. In a comparison of positive and negative groups for the non-extension sign in SM-d cancer, SM invasion was significantly deeper in the positive group than in the negative group $(3012.5 \mu \mathrm{m}$ vs $2002.4 \mu \mathrm{m}$, respectively; $P<$ 0.0001 ) and the rate of lymphovascular invasion was significantly higher in the positive group than in the negative group (63.6\% vs $41.2 \%$, respectively; $P=0.032$ ).

Conclusions The non-extension sign offers high diagnostic specificity for SM-d cancer, and surgery should be considered in patients with a positive non-extension sign.

\section{Introduction}

With the spread of endoscopic treatments such as endoscopic submucosal dissection (ESD) in recent years, low invasiveness has been combined with radical treatment $[1,2]$. In diagnosing the depth of invasion for colorectal cancer (CRC), improved precision is needed to decide whether to perform endoscopic or surgical resection. Lymph node metastasis occurs in approximately $10 \%$ of patients with submucosal (SM) CRC [3-5]. However, risk of lymph node metastasis is not uniform in SM cancer, 
differing according to SM invasion depth and other factors. Lesions with SM invasion limited to less than $1000 \mu \mathrm{m}$, without lymphovascular invasion and/or poorly differentiated components do not result in lymph node metastasis [6]. On the other hand, risk of lymph node metastasis and incomplete removal with endoscopic resection is high with deep submucosal invasive cancer (SM-d: depth of $1000 \mu \mathrm{m}$ or more) and incomplete removal with endoscopic treatment [7], so surgical procedures are principally used in cases of obvious SM-d cancer [8]. Before performing endoscopic treatment, estimating the extent of SM invasion is paramount in deciding the treatment strategy.

In recent years, diagnosing the depth of invasion with colonoscopy has centered on magnifying endoscopy, such as with the pit pattern [9-12] or narrow-band imaging (NBI) [13-15], and many reports have described the usefulness of this approach. Meanwhile, few reports have examined the diagnosis of invasion depth with conventional endoscopic observation, as the basic form of diagnostic endoscopy. Indicators that are considered useful in suggesting SM-d cancer include surface irregularities seen on gross examination of the tumor, depth of depressions, and tension. However, diagnostic performance is thought to be lower with conventional observations than with magnified observations [16].

The "non-extension sign" relates to a localized increase in thickness and rigidity due to deep submucosal invasion. Nagahama et al. [17] reported the non-extension sign as a highly useful diagnostic marker, with $92 \%$ sensitivity and $97.7 \%$ specificity for diagnosing gastric SM-d (depth of $500 \mu \mathrm{m}$ or more) cancer. This non-extension sign can only be seen when the gastric wall is strongly distended through insufflation of a large volume of air. With endoscopic insufflation of air, the area with invasion to the deep SM can be seen as a trapezoid elevation with elevation of the surrounding mucosa.

The aim of the current study was to evaluate the efficacy of the non-extension sign in assessing the optical diagnosis of colorectal SM-d cancer.

\section{Patients and methods}

Participants in this study comprised patients with consecutive early CRC (intramucosal or SM cancer) who underwent endoscopic or surgical resection at Fukuoka University Chikushi Hospital from January 2006 to December 2015 and who received a definitive histopathological diagnosis. Of these, cases in which a single lesion was imaged with the 3 observation methods of chromoendoscopy (CE), magnifying chromoendoscopy (M$\mathrm{CE})$, and magnifying $\mathrm{NBI}(\mathrm{M}-\mathrm{NBI})$ were the subjects of examination. Exclusion criteria were gross morphology showing a pedunculated-type lesion, lesions that were difficult to assess because observation conditions were poor, or lesions identified as colitis-associated CRC.

All patients provided written informed consent to undergo colonoscopic examination. This study was approved by the medical ethics committee of Fukuoka University Chikushi Hospital.
All endoscopic findings were analyzed retrospectively by 2 reviewers (T.H. and H.I.) who had each performed more than 3000 colonoscopies. Original images were transmitted to the server and converted into a compressed format developed using Solemio ENDO (Olympus Optical, Tokyo, Japan). We randomized a list of patients with early CRC that only contained the patient allocation number and date of endoscopy, and endoscopic images were only reviewed on Solemio ENDO. All endoscopic images were reviewed, and CE, M-CE and M-NBI images were evaluated at the same time. Reviewers were blinded to the histopathological diagnosis and the final evaluation of endoscopic findings was decided by the consensus agreement of the 2 reviewers.

\section{Endoscopic procedures}

For bowel preparation, patients followed a low-residue diet and took sodium picosulfate 1 day before the examination, then 2 to $3 \mathrm{~L}$ of polyethylene glycol solution was administered on the morning of the colonoscopy. Scopolamine butylbromide $(10 \mathrm{mg})$ or glucagon $(1 \mathrm{mg})$ was administered in the absence of contraindications, and midazolam $(3-10 \mathrm{mg})$ or diazepam (5-10 mg) was used for conscious sedation only when a patient complained of discomfort or pain. All endoscopic procedures were performed using an electronic endoscopy system (Olympus Optical) with magnifying colonoscopy (CF-Q240ZI, PCFQ240ZI, CF-H260AZI, or PCF-Q260AZI; Olympus Optical).

When CRC was detected during observation with conventional white-light imaging, the tumor surface was washed. To identify the non-extension sign, $0.1 \%$ indigo carmine was sprayed on and around the lesion, air was insufflated into the colon and the colon wall was fully distended and observed. Next, magnified observations were made with $\mathrm{NBI}$ and both vessel pattern and surface pattern were assessed. When magnified observation with $0.1 \%$ indigo carmine dye was not enough for determining the pit pattern or suspected type $\mathrm{V}$ pit pattern, $0.05 \%$ crystal violet dye was applied. After detailed observations, all cancers were resected endoscopically or surgically.

Lesion sites were categorized into 3 groups: proximal colon (including the cecum, ascending colon, and transverse colon), distal colon (including the descending colon and sigmoid coIon), and rectum. Macroscopic classification was performed according to the Japanese classification of colorectal carcinoma [18].

\section{Endoscopic index for SM-d CRC}

\section{CE: non-extension sign}

Indigo carmine $(0.1 \%)$ was sprayed and the colonic wall is strongly extended by endoscopic insufflation of a large volume of air. The area of intramucosal cancer become flattened and extended ( $\triangleright$ Fig.1a). On the other hand, the area of SM-d cancer can be seen as an elevation of the surrounding mucosa due to localized thickening and hardening ( $>$ Fig. $1 \mathbf{b}$ ).

We observed the lesion from the front and oblique or tangential directions. Lesions were assessed as positive for the non-extension sign if any of the following 3 findings were seen. 


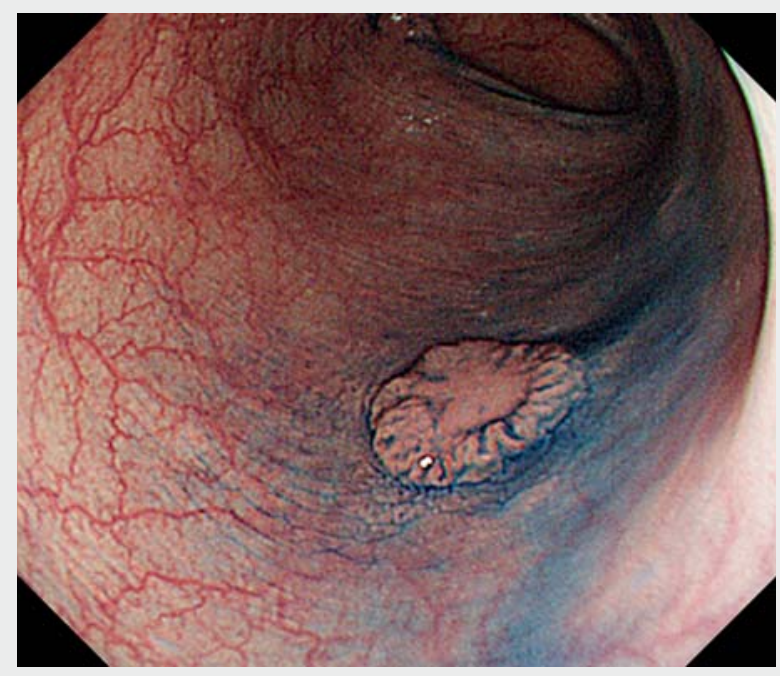

a

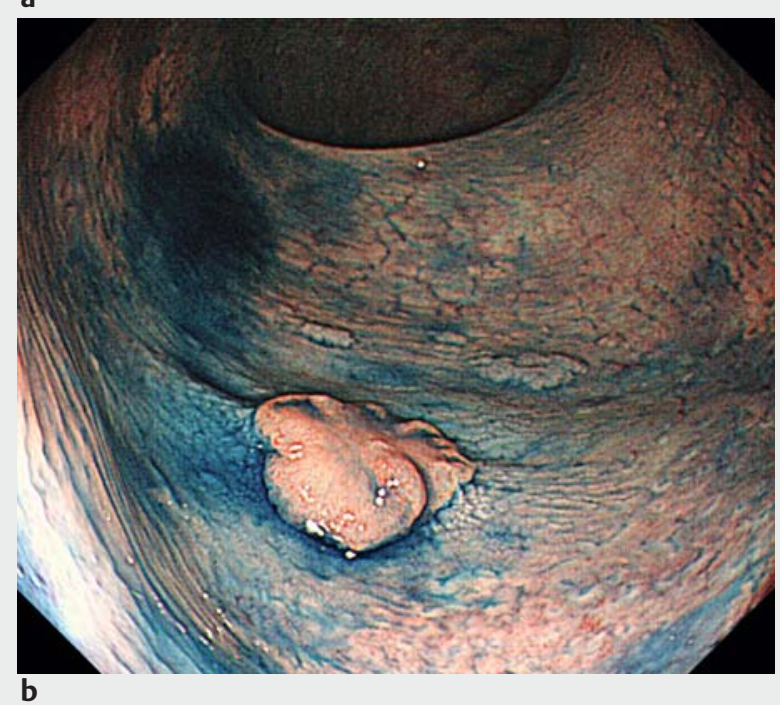

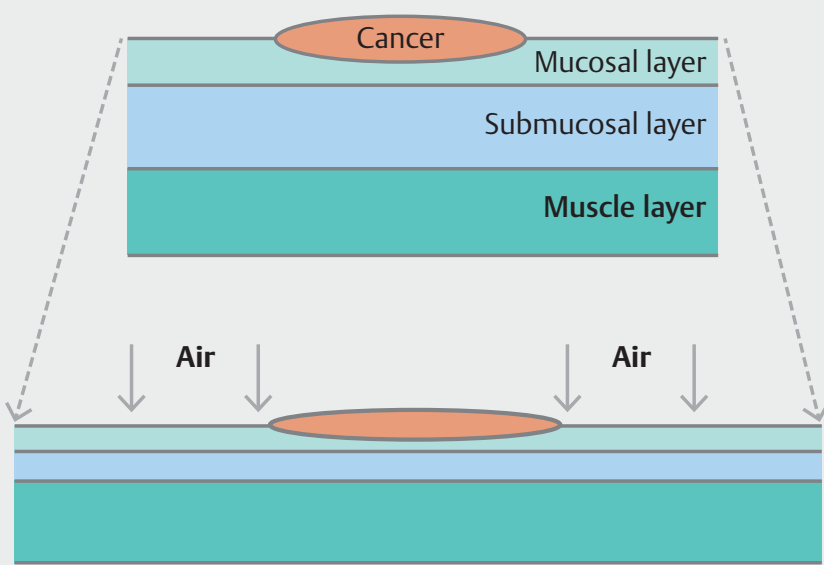

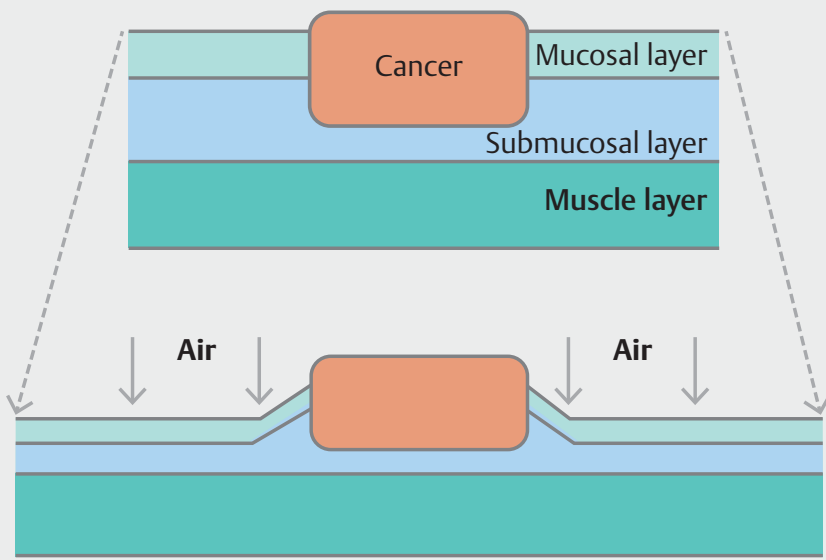

- Fig. 1 Morphological changes with extension of the colonic wall. a The area of surrounding mucosa and intramucosal cancer become flattened and extended. $\mathbf{b}$ The area of SM-d cancer can be seen as an elevation of the surrounding mucosa due to localized thickening and hardening.

1. Rigidity against a background circular arc

When the colon lumen is stretched, normal portions present a circular arc. But the tumor and surrounding portions do not stretch and thus create a more linear appearance ( Fig. 2).

2. Trapezoid elevation

The tumor and normal mucosa around the tumor show trapezoid elevation ( $\triangleright$ Fig. $\mathbf{3}$ ).

3. Converging mucosal folds

Three or more folds converge from the periphery toward the tumor, and elevate at the site of the tumor. Folds converging at 1 point are taken to be negative ( $\triangleright$ Fig. 4 ).

\section{M-CE: classification of pit pattern $\left(V_{1}\right.$ high-grade, $\left.V_{N}\right)$}

This is taken to be positive if type $V_{1}$ high-grade or $V_{N}$ are seen $[9,12]$.

1. $V_{1}$ high-grade

Unclear outline of the pit, irregular margins of the pit, narrowing of the pit, unclear staining characteristics of the areas, scratch sign.

2. $\mathrm{V}_{\mathrm{N}}$

Loss or decrease of pits with an amorphous structure

\section{M-NBI: JNET classification (type 3)}

This is taken as positive if the below findings for vessel pattern and surface pattern are seen [19].

1. Vessel pattern

Loose vessel areas, interruption of thick vessels

2. Surface pattern

Amorphous areas 


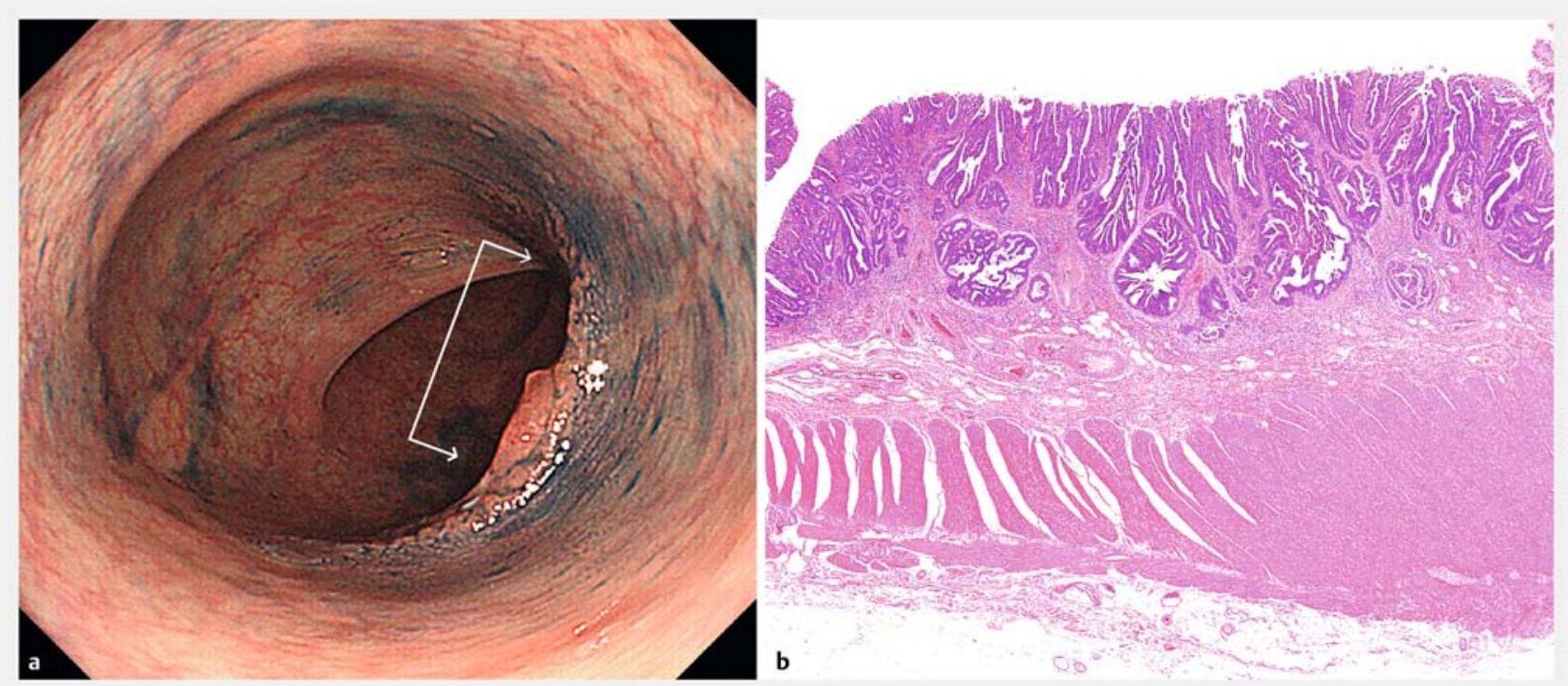

> Fig. 2 Type 0-Ila + Ilc lesion, $25 \mathrm{~mm}$ in diameter. a Rigidity against a background circular arc. When the colon lumen is stretched, normal portions present a circular arc. But the tumor and surrounding portions do not stretch and thus create a more linear appearance (arrow). b Histological findings. well to moderately differentiated adenocarcinoma, pT1 $(1750 \mu \mathrm{m})$.
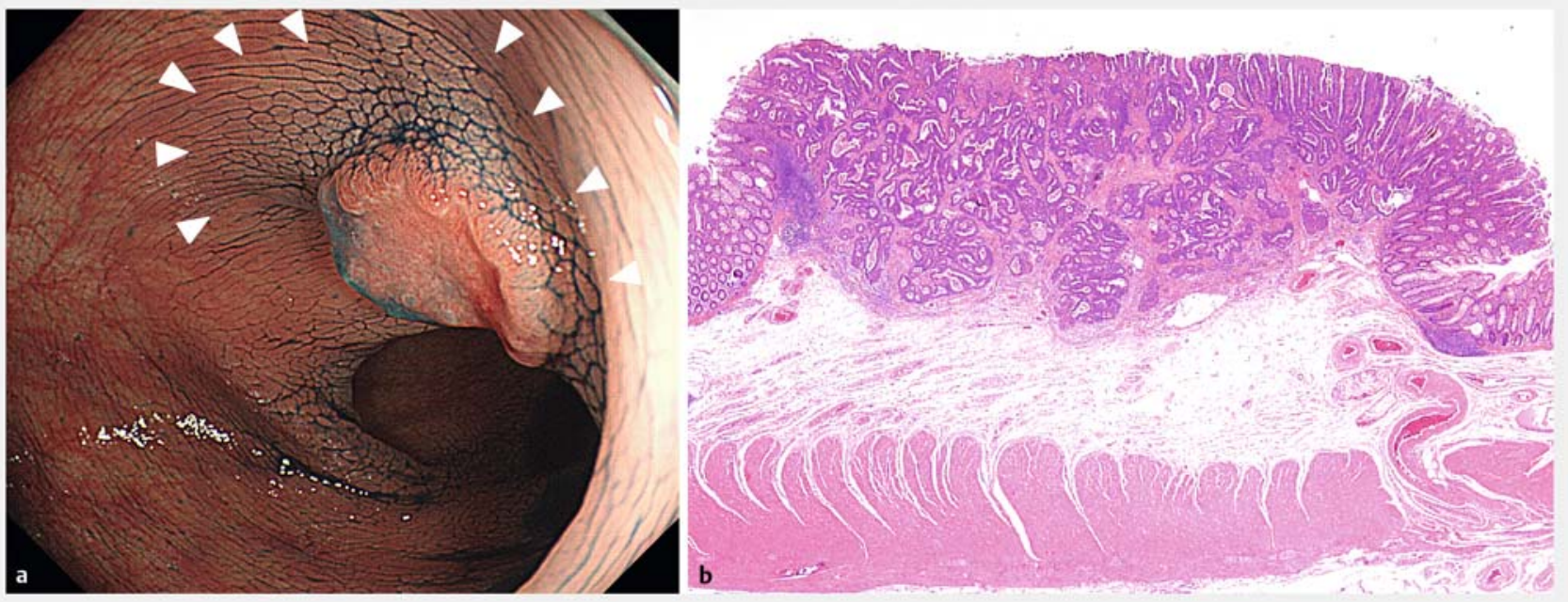

- Fig. 3 Type 0 - Ila + Ilc lesion, $10 \mathrm{~mm}$ in diameter. a Trapezoid elevation. The tumor and normal mucosa around the tumor show trapezoid elevation (arrow head). b Histological findings were well to moderately differentiated adenocarcinoma, pT1 (2600 $\mu \mathrm{m})$.

\section{Histopathological investigations}

All resected specimens were fixed in $20 \%$ buffered formalin solution. These specimens were embedded on paraffin and cut into 2- to 3-mm slices. Each section was subsequently stained with hematoxylin and eosin. Histopathological diagnosis was performed by an experienced pathologist.

In this study, SM-s cancer was defined as vertical invasion into the SM limited to less than $1000 \mu \mathrm{m}$, and SM-d cancer was defined as SM vertical invasion to a depth of $\geq 1000 \mu \mathrm{m}$. The depth of vertical invasion in the SM layer was measured in micrometers from the muscularis mucosae to the deepest cancer gland. When the muscularis mucosae could not be identified owing to carcinomatous invasion, measurement was made from the superficial aspect to the deepest cancer gland [20]. The width of horizontal invasion in the SM layer was measured with the area showing the largest SM invasion on histopathological specimens. The histopathological diagnosis was used as the gold standard. 

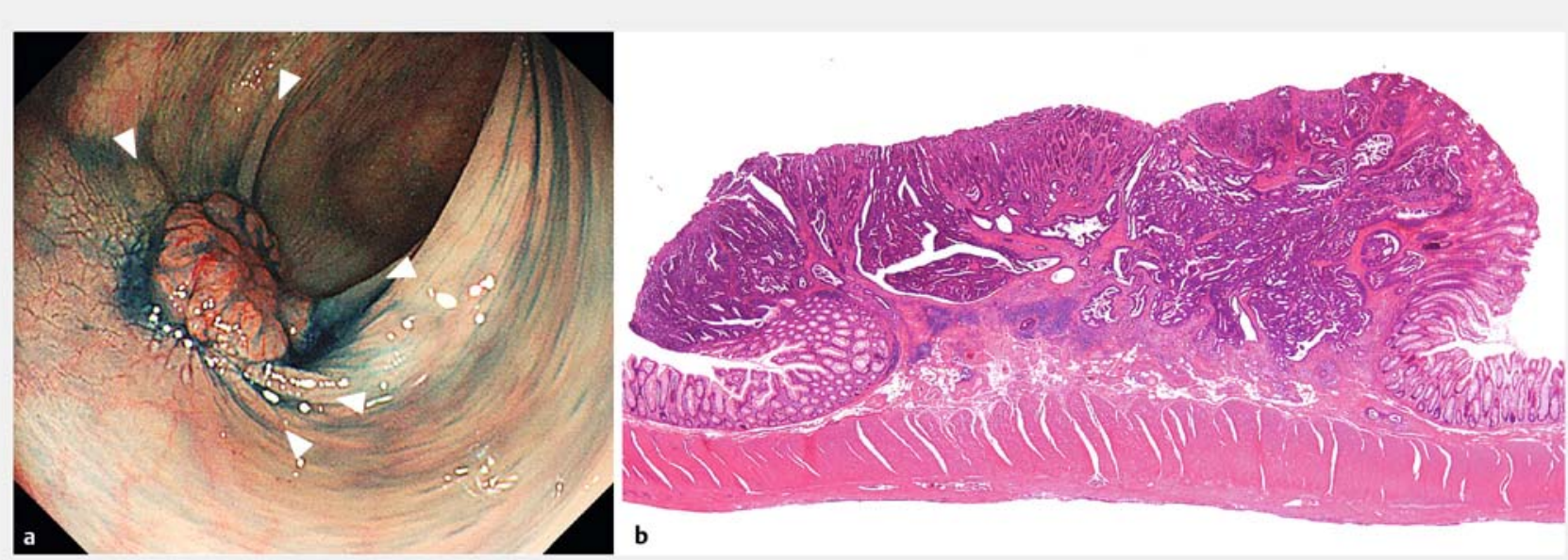

- Fig. 4 Type 0 -Ila + Ilc lesion, $12 \mathrm{~mm}$ in diameter. a Converging mucosal folds. Three or more folds converge from the periphery toward the tumor, and elevate at the site of the tumor (arrow head). b Histological findings were well to moderately differentiated adenocarcinoma, pT1 $(3500 \mu \mathrm{m})$.

\section{Outcome measurements}

For primary outcome measures, the sensitivity, specificity, positive predictive value (PPV), negative predictive value (NPV), and accuracy of each modality in diagnosing SM-d cancer in early CRC were compared.

As secondary outcome measures, diagnostic accuracy for each gross morphology using the non-extension sign was compared. Clinicopathologic findings of positive and negative groups for the non-extension sign in SM-d cancer were investigated. The non-extension sign-positive rate by depth of submucosal invasion in SM cancer was investigated. Interobserver agreement between two reviewers with the three diagnostic modalities of CE, M-CE, and M-NBI was also investigated.

\section{Statistical analysis}

Mean values were compared using the Student's t-test. Comparisons of prevalences between groups were made using the chi-squared test or Fisher's exact test. Values of $P<0.05$ were considered statistically significant. Bonferroni correction was used for the multiple comparison of diagnostic performance for SM-d cancer using the non-extension sign for each macroscopic type and the non-extension sign-positive rate by depth of SM invasion. SPSS version 11.5 J software (SPSS, Chicago, IL) was used for all statistical analyses. Interobserver agreement based on $\mathrm{k}$ statistics was defined as follows: slight, $0-0.2$; fair, $0.21-0.4$; moderate, $0.41-0.6$; substantial, $0.61-0.8$; and almost perfect, $0.81-1$.

\section{Results}

\section{Clinicopathological features}

A total of 623 consecutive early CRCs were resected endoscopically or surgically. Among these, we excluded 136 pedunculated lesions, 22 colitis-associated CRC lesions, 156 lesions for which imaging could not be performed using all three methods of $\mathrm{CE}, \mathrm{M}-\mathrm{CE}$, and $\mathrm{M}-\mathrm{NBI}$, and 16 lesions that were difficult to assess because of poor observation conditions. We analyzed 309 patients with 315 early CRCs in this study. Characteristics of the CRCs identified in this study are summarized in $>$ Table 1 . The male-female ratio was $210: 99$, and mean age was $68.4 \pm 10.1$ years. Mean tumor diameter was $17.5 \pm 10.4 \mathrm{~mm}$ and tumor location was the proximal colon for 82 lesions, the distal colon for 114 lesions, and the rectum for 119 lesions. Macroscopic type was type 0 -Is in 144 lesions, type 0 -Isp in 51 lesions, 0 -Ila in 60 lesions, and 0-Ilc, Ila + Ilc, Ilc + Ila in 60 lesions. The histological finding was intramucosal cancer in 174 lesions, SM-s cancer in 41 lesions, and SM-d cancer in 100 lesions.

\section{Diagnostic performance with each diagnostic modality}

The sensitivity, specificity, PPV, NPV, and accuracy of SM-d cancer diagnosis with each diagnostic modality were $66.0 \%$, $95.8 \%, 88.0 \%, 85.8 \%$, and $86.3 \%$ for CE; $80 \%, 90.7 \%, 80.0 \%$, $90.7 \%$, and $87.3 \%$ for $\mathrm{M}-\mathrm{CE}$; and $65.0 \%, 94.4 \%, 84.4 \%, 85.3 \%$, and $85.1 \%$ for M-NBI, respectively ( $\triangleright$ Table 2 ). The sensitivity of $\mathrm{M}-\mathrm{CE}$ was significantly higher than that of CE ( $80.0 \%$ vs $66.0 \%$, $P=0.026)$. The specificity of CE was significantly higher than that of M-CE ( $95.8 \%$ vs $90.7 \%, P=0.034)$.

Interobserver agreement was categorized as "substantial" for each of CE ( $\mathrm{K}$ value was 0.682 ), M-CE ( $\mathrm{K}$ value was 0.718 ) and $\mathrm{M}-\mathrm{NBI}$ ( $\mathrm{K}$ value was 0.743 ).

\section{Clinical features of the non-extension sign}

The sensitivity, specificity, PPV, NPV, and accuracy of SM-d cancer diagnosis for each macroscopic type using the non-extension sign were $65.0 \%, 97.1 \%, 89.7 \%, 87.8 \%$, and $88.2 \%$ for 0 -Is; $54.5 \%, 100 \%, 100 \%, 88.9 \%$, and $90.2 \%$ for 0 -Isp; $61.1 \%$, $95.5 \%, 84.6 \%, 85.7 \%$, and $85.5 \%$ for 0 -lla; $74.2 \%, 85.2 \%$, $85.2 \%, 74.2 \%$, and $79.3 \%$ for 0 -Ilc, respectively ( Table 3 ). There were no significant differences in the comparison of diagnostic performance between each macroscopic type. 
Table 1 Clinicopathologic characteristics of the patients.

\begin{tabular}{|l|l|}
\hline Gender (male/female) & $210 / 99$ \\
\hline Age (mean \pm SD) & $68.4 \pm 10.1 \mathrm{yrs}$ \\
\hline Tumor size (mean \pm SD) & $17.5 \pm 10.4 \mathrm{~mm}$ \\
\hline Tumor location & \\
\hline - Proximal colon & $82(26.0 \%)$ \\
\hline - Distal colon & $114(36.2 \%)$ \\
\hline - Rectum & $119(37.8 \%)$ \\
\hline Macroscopic types & \\
\hline - 0-Is & $144(45.7 \%)$ \\
\hline - 0-Isp & $51(16.2 \%)$ \\
\hline - 0-Ila & $60(19.0 \%)$ \\
\hline - 0-Ilc· Ila + IIc·Ilc + Ila & $60(19.0 \%)$ \\
\hline Histological findings & \\
\hline - Intramucosal cancer & $174(55.2 \%)$ \\
\hline - SM-s cancer & $41(13.0 \%)$ \\
\hline - SM-d cancer & $100(31.7 \%)$ \\
\hline $\begin{array}{l}\text { SD, standard deviation; SM-s, submucosal invasion depth<1000 } \mu \mathrm{m} ; \\
\text { SM-d, submucosal invasion depth } \geq 1000 \mu \mathrm{m} .\end{array}$ \\
\hline
\end{tabular}

In a comparison of positive and negative groups for the nonextension sign in SM-d cancer, SM invasion was significantly deeper in the positive group than in the negative group $(3012.5 \pm 1121.5 \mu \mathrm{m}$ vs $2002.4 \pm 1215.8 \mu \mathrm{m}$, respectively; $P<$ $0.0001)$. SM invasion was also significantly wider in the positive group than in the negative group $(5465.2 \pm 2593.2 \mu \mathrm{m}$ vs $3217.6 \pm 2116.4 \mu \mathrm{m}$, respectively; $P<0.0001)$. The rate of lymphovascular invasion (lymphatic invasion and/or venous invasion) was significantly higher in the positive group than in the negative group ( $63.6 \%$ vs $41.2 \%, P=0.032$ ). In cases of surgical resection, lymph node metastasis was seen in 3 of 56 (5.4\%) non-extension sign-positive patients, as compared with 0 of 27 (0\%) non-extension sign-negative patients, showing no significant difference ( $P=0.547)$ ( $>$ Table 4).

In an investigation of the non-extension sign positive rate by depth of vertical invasion in SM cancer, the positive rate for less than $1000 \mu \mathrm{m}(12.2 \%)$ was significantly lower than that for $2000-2999 \mu \mathrm{m}(71.9 \%, P<0.0001)$ and $\geq 3000 \mu \mathrm{m}(89.2 \%, P<$ $0.0001)$ ( $>$ Table 5).

\section{Discussion}

In the current investigation, diagnostic accuracy of colorectal SM-d cancer diagnosis using the non-extension sign on CE was not found to be significantly different from that using M-CE or $\mathrm{M}-\mathrm{NBI}$. However, the specificity of CE was significantly higher than that of M-CE. This suggests that surgery should be considered if the non-extension sign is positive.

In recent years, diagnostic endoscopy has come to be centered on magnifying endoscopic observations, and the pit pattern classification proposed by Kudo et al. [9] and many other techniques have been reported. When cancer has invaded deep into the SM, the ductal structure is broken or desmoplastic reactions occur, causing erosive change in the surface epithelium and breakdown of the surface structure [12,21,22]. Moreover, as the degree of histological atypia increases in colorectal tumor lesions and angiogenesis progresses, the diameter and density of the blood vessels increase [23]. Magnifying

- Table 2 Diagnostic performance of SM-d cancer with each diagnostic modality.

\begin{tabular}{|c|c|c|c|c|c|}
\hline & $\begin{array}{l}\text { Sensitivity, \% } \\
(95 \% \mathrm{CI})\end{array}$ & $\begin{array}{l}\text { Specificity, \% } \\
(95 \% \mathrm{CI})\end{array}$ & $\begin{array}{l}\text { PPV, \% } \\
(95 \% \mathrm{CI})\end{array}$ & $\begin{array}{l}\text { NPV, \% } \\
(95 \% \mathrm{CI})\end{array}$ & $\begin{array}{l}\text { Accuracy, \% } \\
(95 \% \mathrm{Cl})\end{array}$ \\
\hline CE & $66.0(60.2-69.9)$ & $95.8(93.1-97.6)$ & $88.0(80.3-93.2)$ & $85.8(83.4-87.5)$ & $86.3(82.7-88.8)$ \\
\hline $\mathrm{M}-\mathrm{CE}$ & $80.0(73.6-85.1)$ & $90.7(87.7-93.0)$ & $80.0(73.6-85.1)$ & $90.7(87.7-93.0)$ & $87.3(83.3-90.5)$ \\
\hline $\mathrm{M}-\mathrm{NBI}$ & $65.0(58.8-69.5)$ & $94.4(91.6-96.5)$ & $84.4(76.4-90.3)$ & $85.3(82.7-87.2)$ & $85.1(81.2-88.0)$ \\
\hline
\end{tabular}

SM-d, submucosal invasion depth>1000 $\mu \mathrm{m}$; CE, chromoendoscopy; $\mathrm{M}-\mathrm{CE}$, magnifying chromoendoscopy; M-NBI, magnifying narrow band imaging; CI, confidence interval; PPV, positive predictive value; NPV, negative predictive value.

- Table 3 Diagnostic performance for SM-d cancer using non-extension sign for each macroscopic type.

\begin{tabular}{|c|c|c|c|c|c|}
\hline & $\begin{array}{l}\text { Sensitivity, \% } \\
(95 \% \mathrm{Cl})\end{array}$ & $\begin{array}{l}\text { Specificity, \% } \\
(95 \% \text { CI) }\end{array}$ & $\begin{array}{l}\text { PPV, \% } \\
(95 \% \mathrm{Cl})\end{array}$ & $\begin{array}{l}\text { NPV, \% } \\
(95 \% \mathrm{CI})\end{array}$ & $\begin{array}{l}\text { Accuracy, \% } \\
\text { (95\% CI) }\end{array}$ \\
\hline 0 -Is & $65.0(55.3-69.8)$ & $97.1(93.4-99.0)$ & $89.7(76.3-96.3)$ & $87.8(84.5-89.5)$ & $88.2(82.8-90.9)$ \\
\hline 0 -Isp & $54.5(35.8-54.5)$ & $100(94.9-100)$ & $100(65.7-100)$ & $88.9(84.3-88.9)$ & $90.2(82.1-90.2)$ \\
\hline 0 -Ila & $61.1(44.9-68.9)$ & $95.5(88.8-98.6)$ & $84.6(62.2-95.4)$ & $85.7(79.8-88.6)$ & $85.5(76.1-90.0)$ \\
\hline $0-\|c \cdot\| a+\|c \cdot\| c+\| a$ & $74.2(63.1-81.2)$ & $85.2(72.4-93.3)$ & $85.2(72.4-93.3)$ & $74.2(63.1-81.2)$ & $79.3(67.4-86.9)$ \\
\hline
\end{tabular}

SM-d, submucosal invasion depth>1000 $\mu \mathrm{m}$; Cl, confidence interval; PPV, positive predictive value; NPV, negative predictive value. 
- Table 4 Comparison of positive and negative groups for the non-extension sign in SM-d cancer.

\begin{tabular}{|c|c|c|c|}
\hline & $\begin{array}{l}\text { Non-extension sign positive, } \\
n=66\end{array}$ & $\begin{array}{l}\text { Non-extension sign negative, } \\
\mathrm{n}=34\end{array}$ & $P$ value \\
\hline Tumor size (mean \pm SD) & $16.2 \pm 6.3 \mathrm{~mm}$ & $18.2 \pm 8.4 \mathrm{~mm}$ & 0.204 \\
\hline \multicolumn{4}{|l|}{ Tumor location } \\
\hline - Proximal colon & $17(25.8 \%)$ & $12(35.3 \%)$ & 0.319 \\
\hline - Distal colon & $30(45.5 \%)$ & $12(35.3 \%)$ & 0.32 \\
\hline - Rectum & $19(28.8 \%)$ & $10(29.4 \%)$ & 0.948 \\
\hline \multicolumn{4}{|l|}{ Macroscopic types } \\
\hline . $0-\mathrm{Is}$ & $26(39.4 \%)$ & $14(41.2 \%)$ & 0.863 \\
\hline . 0 -Isp & $6(9.1 \%)$ & $5(14.7 \%)$ & 0.502 \\
\hline . 0-IIa & $11(16.7 \%)$ & $7(20.6 \%)$ & 0.629 \\
\hline - $0-\|c \cdot\| a+\|c \cdot\| c+\| a$ & $23(34.8 \%)$ & $8(23.5 \%)$ & 0.246 \\
\hline Depth of submucosal invasion & $3012.5 \pm 1121.5 \mu \mathrm{m}$ & $2002.4 \pm 1215.8 \mu \mathrm{m}$ & $<0.0001$ \\
\hline Width of submucosal invasion & $5465.2 \pm 2593.2 \mu \mathrm{m}$ & $3217.6 \pm 2116.4 \mu \mathrm{m}$ & $<0.0001$ \\
\hline Lymphovascular invasion & $42(63.6 \%)$ & $14(41.2 \%)$ & 0.032 \\
\hline Lymph node metastasis & $3 / 56(5.4 \%)$ & $0 / 27(0 \%)$ & 0.547 \\
\hline
\end{tabular}

D Table 5 The non-extension sign-positive rate by depth of submucosal invasion in submucosal cancer.

\begin{tabular}{|c|l|l|}
\hline $\begin{array}{l}\text { Depth of vertical invasion } \\
\text { in the submucosal layer }\end{array}$ & $\begin{array}{l}\text { Positive rate of non- } \\
\text { extension sign }\end{array}$ & P value \\
\hline$<1000 \mu \mathrm{m}$ & $12.2 \%(5 / 41)$ & \\
\hline $1000-1999 \mu \mathrm{m}$ & $32.3 \%(10 / 31)$ & $0.031^{1}$ \\
\hline $2000-2999 \mu \mathrm{m}$ & $71.9 \%(23 / 32)$ & $<0.001^{2}$ \\
\hline$\geq 3000 \mu \mathrm{m}$ & $89.2 \%(23 / 37)$ & $<0.001^{3}$ \\
\hline $\begin{array}{l}1 \\
212.2 \% \text { vs. } 32.3 \%\end{array}$ & & \\
\hline $\begin{array}{l}12.2 \% \text { vs. } 71.9 \% \\
312.2 \% \text { vs. } 89.2 \%\end{array}$ & & \\
\hline
\end{tabular}

endoscopic observations is superior in visualizing these surface structures. On the diagnostic performance of SM-d cancer with the pit pattern classification, pooled estimates from a meta-analysis were $81 \%$ for sensitivity and $95 \%$ for specificity. With regard to the diagnostic performance for SM-d cancer with NBI, pooled estimates from the same meta-analysis were $77 \%$ for sensitivity and $98 \%$ for specificity [16].

While assessments of surface structure using magnifying endoscopy are very useful, colon cancer in which the surface structure is maintained while invasion to the submucosa occurs is not uncommon. With such lesions, accurate diagnoses are not made using information from the surface of the lesion only, and conventional observations are also useful. Moreover, systematic use of advanced imaging and documentation of endoscopic features is not yet widely performed in daily clinical practice in Western countries. Specific equipment is required for both NBI (i.e., magnifying endoscope with NBI function) and MCE (i.e., magnifying endoscope and dye solution) that is not available in all hospitals [16]. The useful conventional endoscopic features are in demand until now. In conventional observations, gross tumor findings that have been proposed to indicate SM-d cancer include loss of lobulation, bleeding, demarcated depressed area, and fullness [24,25]. However, in a review [16] of 6 studies on SM-d cancer that include these reports, specificity reportedly ranged from 0.80 to 0.98 , while sensitivity was much lower, varying from 0.18 to 0.68 . Advanced imaging techniques were concluded to allow an almost twofold better recognition of deep invasion as compared with gross morphological features seen on conventional views. The low sensitivity of SM-d cancer by conventional endoscopy is due to the low prevalence of obvious non-structure surface. Moreover, the conventional endoscopic feature of SM-d cancer of the previous studies were not sufficiently defined and not unified. Determinations of the surface properties of tumors are difficult under conventional observation techniques, and experience is needed in making such judgments.

Non-extension signs such as rigidity of circular arc, trapezoid elevation, and converging mucosal folds are simple indicators for assessing the morphology of surrounding mucosa rather than surface properties of the tumor such as loss of lobulation, bleeding, demarcated depressed area, and fullness. Prospective investigations are needed in the future, but interobserver agreement for the non-extension sign was substantial and may offer a useful, relatively objective indicator. Moreover, the non- 
extension sign can only be seen when the colorectal wall is strongly distended through insufflation of a large volume of air. This finding is produced when the intestinal wall in the lesion site becomes rigid as a result of the cancer invading the $\mathrm{SM}$ and forming cancer nests in association with desmoplastic reactions [17]. In the current investigation of the colon, mean SM invasion depth in SM-d cancer patients positive for the non-extension sign was $3012 \mu \mathrm{m}$, and mean SM invasion width was $5465 \mu \mathrm{m}$. The non-extension sign is considered to reflect the existence of solid cancer nests in the SM. Known risk factors for lymph node metastasis from SM cancer include submucosal vertical invasion depth $\geq 1000 \mu \mathrm{m}$, vascular invasion (lymphatic invasion and/or venous invasion), poorly differentiated adenocarcinoma and mucinous carcinoma, and tumor budding [6, $26,27]$. In this study, the rate of lymphovascular invasion was significantly higher in the non-extension sign-positive group than in the negative group. This investigation suggests the possibility that the non-extension sign is predictive of 2 risk factors (SM invasion depth and lymphovascular invasion) for lymph node metastasis in SM cancer.

The significantly lower sensitivity of CE compared to M-CE may be due to several factors. First, the false-negative rate has been reported as high if the gastric cancer is not examined from an oblique or tangential direction [17]. However, unlike the stomach, the colon has many curves and the lumen is narrow, so adequate observations often cannot be made from an oblique or tangential direction. The second is that the positive rate for the non-extension sign with an SM depth of $1000-$ $1999 \mu \mathrm{m}$ was lower compared with lesions that had invaded to depths $>2000 \mu \mathrm{m}$. The non-extension sign thus may miss SM-d cancer with shallow invasion in the SM layer. For these reasons, additional M-CE is necessary to detect SM-d cancer with shallow invasion in the SM layer if the non-extension sign is negative, because the non-extension sign has low sensitivity and NPV. Conversely, additional M-CE can be omitted and surgery should be considered if the non-extension sign is positive, because the non-extension sign offers high specificity and PPV.

The classification system for NBI diagnosis in this study was made using the Japan NBI Expert Team (JNET) classification [19] as an index, a classification proposed to establish a universal NBI magnifying endoscopic classification of colorectal tumors in 2014. The JENT classification defines 4 types (Types 1, 2A, $2 \mathrm{~B}$ and 3 ) based on vessel and surface patterns. The characteristics of Type 3 are loose vessel areas or interruption of thick vessels and an amorphous surface pattern. Sumimoto et al [28]. evaluated the relationship between JNET classification and histological findings. The sensitivity and specificity of Type 3 lesions for the diagnosis of SM-d carcinoma were $55.4 \%$ and 99.8\%. Sensitivity was thus low, similar to our report.

This study has some inherent limitations that need to be considered. First, the investigation was a retrospective study at a single institution and endoscopic findings in this study were evaluated by two experts. Prospective studies and future evaluations will need to include non-experts. Furthermore, because the focus of this study was early colorectal cancer, the usefulness of the non-extension sign in colorectal neoplasia including adenomas will need to be clarified in a future study.
Second, selection bias may have been present, since only lesions observed using all 3 diagnostic methods were included for analysis. All endoscopic images were reviewed, and the number of reviewed images differed between patients. CE, M$\mathrm{CE}$ and $\mathrm{M}-\mathrm{NBI}$ images were evaluated the same time, which could have led to a carryover effect during diagnosis.

\section{Conclusion}

In conclusion, accurate diagnosis and the ability to obtain specimens that can be adequately examined histopathologically is of paramount importance in deciding subsequent treatment strategies and postoperative follow-up. The non-extension sign reflects presence of solid cancer nests in the SM layer, and also correlates highly with lymphovascular invasion.

\section{Competing interests}

\section{None}

\section{References}

[1] Nakajima T, Saito Y, Tanaka S et al. Current status of endoscopic resection strategy for large, early colorectal neoplasia in Japan. Surg Endosc 2013; 27: $3262-3270$

[2] Fujiya M, Tanaka K, Dokoshi T et al. Efficacy and adverse events of EMR and endoscopic submucosal dissection for the treatment of coIon neoplasms: a meta-analysis of studies comparing EMR and endoscopic submucosal dissection. Gastrointest Endosc 2015; 81: 583 595

[3] Minomoto T, Mai M, Ogino T et al. Early invasive colorectal carcinomas metastatic to the lymph node with attention to their nonpolypoid development. Am J Gastroenterol 1993; 88: 1035-1039

[4] Nusko G, Mansmann U, Partzsch U et al. Invasive carcinoma in colorectal adenomas: Multivariate analysis of patient and adenoma characteristics. Endoscopy 1997; 29: 626-631

[5] Sakuragi M, Togashi K, Konishi F et al. Predictive factors for lymph node metastasis in T1 stage colorectal carcinomas. Dis Colon Rectum 2003; 46: $1626-1632$

[6] Kitajima K, Fujimori T, Fujii S et al. Correlation between lymph node metastasis and depth of submucosal inavasion in submucosal invasive colorectal carcinoma: a Japanese collaborative study. J Gastroenterol 2004; 39: 534- 543

[7] Bosch SL, Teerenstra S, de Wilt JH et al. Predicting lymph node metastasis in PT1 colorectal cancer: a systematic review of risk factors providing rationale for therapy decision. Endoscopy 2013; 45: 827834

[8] Tanaka S, Kashida H, Saito Y et al. JGES guidelines for colorectal endoscopic submucosal dissection/endoscopic mucosal resection. Dig Endosc 2015; 27: $417-434$

[9] Kudo S, Rubio CA, Teixeira CR et al. Pit pattern in colorectal neoplasia: endoscopic magnifying view. Endoscopy 2001; 33: 367-373

[10] Tanaka S, Kaltenbach T, Chayama K et al. High-magnification colonoscopy (with video). Gastrointest Endosc 2006; 64: 604-613

[11] Matsuda T, Fujii T, Saito Y et al. Efficacy of the invasive/non-invasive pattern by magnifying chromoendoscopy to estimate the depth of invasion of early colorectal neoplasms. Am J Gastroenterol 2008; 103: $2700-2706$ 
[12] Wada Y, Kashida H, Kudo SE et al. Diagnostic accuracy of pit pattern and vascular pattern analysis in colorectal lesions. Dig Endosc 2010; 22: $192-199$

[13] Sano Y, Horimatsu T, Fu KI et al. Magnifying observation of microvascular architecture of colorectal lesions using a narrow band imaging system. Dig Endosc 2006; 18: S44-S51

[14] Tanaka S, Hirata M, Oka S et al. Clinical significance of narrow band imaging (NBI) in diagnosis and treatment of colorectal tumor. Gastroenterol Endosc 2008; 50: 1289-1297

[15] Hisabe T, Yao K, Beppu T et al. Validity of the usefulness of microvascular architecture and microsurface structure using magnifying endoscopy with narrow-band imaging in the colorectal neoplasm. Ann Gastroenterol 2013; 26: 45 - 51

[16] Backes Y, Moss A, Reitsma JB et al. Narrow Band Imaging, Magnifying Chromoendoscopy, and Gross Morphological Features for the Optical Diagnosis of T1 Colorectal Cancer and Deep Submucosal Invasion: A Systematic Review and Meta-Analysis. Am J Gastroenterol 2017; 112: $54-64$

[17] Nagahama T, Yao K, Imamura K et al. Diagnostic performance of conventional endoscopy in the identification of submucosal invasion by early gastric cancer: the "non-extension sign" as a simple diagnostic marker. Gastric Cancer 2017; 20: 304-313

[18] Japanese Society for Cancer of the Colon and Rectum. Japanese classification of colorectal carcinoma. $2^{\text {nd }}$ English Edition. Tokyo: Kanehara \& Co: Endoscopy; Ltd; 2009 (Endoscopic Classification Review Group. Update on the Paris classification of superficial neoplastic lesions in the digestive tract. 2005; 37: 570-578

[19] Sano Y, Tanaka S, Kudo SE et al. Narrow-band imaging (NBI) magnifying endoscopic classification of colorectal tumors proposed by the Japan NBI Expert Team. Dig Endosc 2016; 28: 526-533
[20] Matsumoto K, Nagahara A, Terai T et al. Evaluation of new subclasssification of type $V(I)$ pit pattern for determining the depth and type of invasion of colorectal neoplasm. J Gastroenterol 2011; 46: 31 - 33

[21] Ohta A, Tominaga K, Sakai Y. Efficacy of magnifying colonoscopy for the diagnosis of colorectal neoplasia: comparison with histopathological findings. Dig Endosc 2004; 16: $308-314$

[22] Nagata S, Tanaka S, Haruma K et al. Pit pattern diagnosis of early colorectal carcinoma by magnifying colonoscopy: clinical and histological implications. Int J Oncol 2000; 16: 927 -934

[23] Konerding MA, Fait E, Gaumann A. 3D microvascular architecture of pre-cancerous lesions and invasive carcinomas of the colon. Br J Cancer 2001; 84: $1354-1362$

[24] Ikehara H, Saito Y, Matsuda T et al. Diagnosis of depth of invasion for early colorectal cancer using magnifying colonoscopy. J Gastroenterol Hepatol 2010; 25: $905-912$

[25] Jang HW, Park SJ, Cheon JH et al. Does magnifying narrow-band imaging or magnifying chromoendoscopy help experienced endoscopists assess invasion depth of large sessile and flat polyps? Dig Dis Sci 2014; 59: 1520 - 1528

[26] Nakadoi K, Tanaka S, Kanao H et al. Management of T1 colorectal carcinoma with special reference to criteria for curative endoscopic resection. J Gastroenterol Hepatol 2011; 27: 1057 -1062

[27] Ikematsu H, Yoda Y, Matsuda T et al. Long-term outcomes after resection for submucosal invasive colorectal cancers. Gastroenterol 2013; 144: $551-559$

[28] Sumimoto K, Tanaka S, Shigita K et al. Clinical impact and characteristics of the narrow-band imaging magnifying endoscopic classification of colorectal tumors proposed by the Japan NBI Expert Team. Gastrointest Endosc 2017; 85: 816-821 